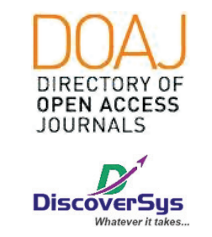

Published by DiscoverSys

\title{
The accuracy of automated oscillometry compared to manual doppler in measuring ankle brachial index in suspected peripheral arterial disease patients: a systematic review
}

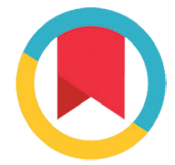

CrossMark

\author{
Achmad Ismail Sampurna Putra*
}

\section{ABSTRACT}

Background: Golden standard to diagnose Peripheral Artery Disease (PAD) is angiography. A more common and practical alternative technique is by calculating Ankle Brachial Index (ABI) using Oscillometry as systolic blood pressure measurement. Though, its accuracy remains obscure.

Methods: A systematic search was performed using PubMed and Google Scholar database. There were 11 articles were found after reviewed for the title and abstract by inclusion and exclusion criteria. However, only 6 articles were relevant and used by the authors.

Results: Based on the six journals appraised, the sensitivity of automated oscillometry in detecting PAD $(A B I<0.9)$ ranged from 0.4-0.7. The specificity, however, showed better result around 0.75-1. It shows that those patients who scored negative for PAD with oscillometry are not likely to have the disease. Automated oscillometry in studies appraised was also seen to have moderate positive and negative predictive value, which may indicate the possibility of this simpler diagnostic tool to be used to screen PAD. Most of the studies demonstrated good likelihood ratio for oscillometry, which even adds more power to oscillometry as a PAD diagnostic tool.

Conclusion: Automated oscillometry was comparable with manual Doppler due to its high specificity. Several advantages were identified such as; oscillometry required less reliant on the specialized skills, commonly available, reliable, and simple to use which can be performed by primary care physicians even in their primitive set up. Thus, the oscillometric method can be utilized as an alternative in diagnosing patients suspected with PAD.
Faculty of Medicine University of Indonesia, Jakarta-Indonesia

*Correspondence to: Achmad Ismail Sampurna Putra Faculty of Medicine University of Indonesia, Jakarta-Indonesia achmadismailputragmail.com

Diterima: 2018-01-18 Disetujui: 2018-04-29

Diterbitkan: 2018-05-1

Keywords: Oscillometric, doppler, ABI, PAD

Cite This Article: Putra, A.I.S. 2018. The accuracy of automated oscillometry compared to manual doppler in measuring ankle brachial index in suspected peripheral arterial disease patients: a systematic review. Intisari Sains Medis 9(2): 137-140. D0I: 10.1556/ism.v9i2.152

\section{INTRODUCTION}

\section{Background}

Peripheral Artery Disease (PAD) is one of the least recognized and treated forms of atherosclerosis. The diagnosis of PAD is important for its prognostic factor and treatment to reduce cardiovascular morbidity and mortality. ${ }^{1}$ However, the diagnosis of PAD is seldom established for its gold standard for diagnosis is angiography on the symptomatic extremity. ${ }^{2}$

Ankle-Brachial Index (ABI) is a non-invasive technique developed to diagnose PAD. ABI is calculated by dividing the systolic pressure of the affected lower extremity by the systolic pressure of the brachial artery represented as a ratio. ABI of $<0.9$ has up to $90 \%$ sensitivity to diagnose PAD. ${ }^{1,3}$ Doppler ultrasound serves as a gold standard in the measurement of systolic blood pressure in both the ankle and brachial artery. ${ }^{2}$ Doppler ultrasound is a hindrance to primary care in Indonesia due to the availability of both the device and its competent operator. On the other hand, oscillometry is an approved technique for the measurement of blood pressure that is commonly available and easy to use. ${ }^{3}$ Oscillometry measures systolic blood pressure by detecting the peak oscillation during deflation of the cuff from the suprasystolic pressure. ${ }^{4}$

\section{Clinical Question}

How accurate is automatic oscillometry compared to manual doppler and Korotkoff in measuring ankle brachial index in suspected pad patients?

\section{METHODS}

\section{Search Strategy}

The search was performed on PubMed and Google Scholar on May 29, 2014. The search tool was used which contains keywords including "ankle-brachial index," "automated oscillometer," "peripheral arterial disease," "manual Doppler," and related terms (Table 1). Search strategy, results, and the inclusion and exclusion criteria are included in a flowchart (Figure 1).

\section{SELECTION}

The systematic search was done using limitations articles in English, published within the last 10 years and available in full text for free. The search resulted 
in 11 articles after filtering for double articles from both databases. Studies other than cross-sectional are excluded. There was a total of 6 articles that are usable after full-text reading.

The 6 relevant articles, Premanath et al, ${ }^{5}$ Kornø et al, ${ }^{6}$ Takahashi et al, ${ }^{7} \mathrm{McD}$ ougall et al, ${ }^{8}$ Beckman et al, ${ }^{1}$ dan Clairotte et al, ${ }^{1}$ were apprised in groups by 4 authors using standardized validity criteria for the diagnostic study. The critical appraisal was performed by considering the validity, importance, and applicability of the articles. The checklist used was "Oxford Critical Appraisal Toolkit" which is available from www.bmj.com.

\section{RESULT}

The relevance of six of the studies was elaborated into whether the study used a similar group of patients, intervention, comparison, as well as

Table 1 Search Strategy Used in PubMed and Google Scholar, conducted on May 29, 2014

\begin{tabular}{llc}
\hline Source & Search Terms & $\begin{array}{c}\text { Articles } \\
\text { Found }\end{array}$ \\
\hline PubMed & $\begin{array}{l}\text { (((Ankle-brachial index) AND automated oscillometer) } \\
\text { AND manual Doppler) AND peripheral arterial disease }\end{array}$ & 8 \\
Google & $\begin{array}{l}\text { Ankle-brachial index AND automated oscillometer AND } \\
\text { manual Doppler AND peripheral arterial disease }\end{array}$ & 7 \\
Scholar & \\
\hline
\end{tabular}

outcome (Table 2). Validity was assessed from the independence of the test, blinding of each study, appropriateness of the population studied, as well as the use of the standard procedure for both index and reference test. Importance was analyzed starting from the prevalence of the outcome in a population study, followed by sensitivity, specificity, and most importantly positive and negative predictive value of the diagnostic tool tested. Also, likelihood ratio for positive and negative results was calculated to increase the accuracy of the tool in diagnosing the disease. Lastly, applicability was assessed to see whether all studies can be implemented in daily practice.

Premanath et al. ${ }^{5}$ conducted a cross-sectional study of diabetic patients who have high risk in developing PAD. Twelve out of 120 males and six out of 80 females were ABI positive with oscillometry. Both sensitivity and specificity were moderate, with a high negative predictive value of 0.96 . It indicated that patients with negative oscillometry reading are not likely to have the PAD.

Kormo, et al. ${ }^{6}$ study was done in a cross-sectional way in which $A B I$ was measured in 61 patients admitted to the department of vascular surgery. In this study, the prevalence of PAD was 2.3 that is the highest among any of compared studies. This study has shown good specificity of 0.92 compared to the sensitivity of 0.71 . It was discovered that oscillometry is best performed on low $\mathrm{ABI}(<0.90)$ because

Table 2 Critical Appraisal from 6 Relevant Articles Based on Their Validity, Importance, and Applicability

\begin{tabular}{|c|c|c|c|c|c|c|c|c|c|c|c|c|c|c|}
\hline 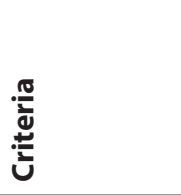 & 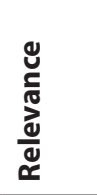 & & & 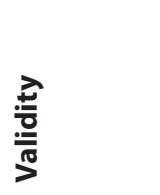 & & & & 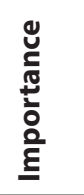 & & & & & & 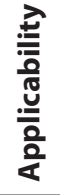 \\
\hline$\frac{\underline{u}}{\underline{\underline{t}}}$ & 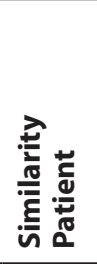 & 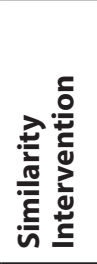 & 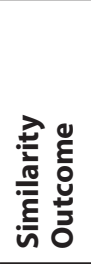 & 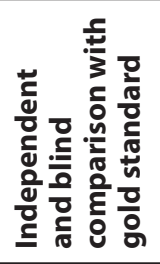 & $\begin{array}{l}\frac{y}{5} \\
\frac{\pi}{2} \\
\frac{2}{0} \\
\frac{0}{2} \\
\frac{2}{2}\end{array}$ & 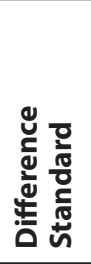 & 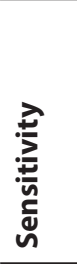 & 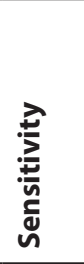 & 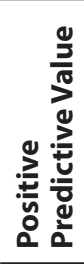 & 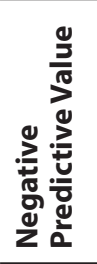 & 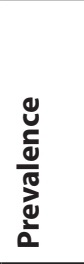 & 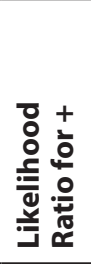 & 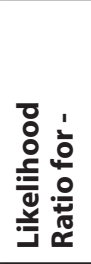 & 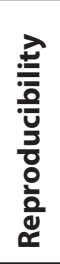 \\
\hline $\begin{array}{l}\text { Premanath, } \\
\text { et al. }\end{array}$ & - & + & + & + & + & + & 0.7 & 0.75 & 0.65 & 0.96 & 0.1 & 2.8 & 0.4 & + \\
\hline $\begin{array}{l}\text { Kormo, } \\
\text { et al. }\end{array}$ & & & + & - & + & + & 0.71 & 0.92 & 0.65 & 0.66 & 2.3 & 7.1 & 0.31 & + \\
\hline $\begin{array}{l}\text { Takahashf, } \\
\text { et al }\end{array}$ & - & + & + & + & - & + & 0.5 & 1 & 1 & 0.95 & 0.09 & & 0.5 & + \\
\hline $\begin{array}{l}\text { McDoug all, } \\
\text { et al. }\end{array}$ & - & + & + & - & - & + & 0.71 & 0.89 & 0.8 & 0.77 & 0.28 & 6.45 & 0.33 & + \\
\hline $\begin{array}{l}\text { Beckman, } \\
\text { et al. }\end{array}$ & + & + & + & + & + & + & 0.73 & 0.95 & 0.88 & 0.77 & 0.27 & 14.6 & 0.28 & + \\
\hline $\begin{array}{l}\text { Clairotte, } \\
\text { et al. }\end{array}$ & - & + & + & + & + & + & 0.4 & 0.96 & 0.66 & 0.88 & 0.33 & 9 & 0.63 & + \\
\hline
\end{tabular}




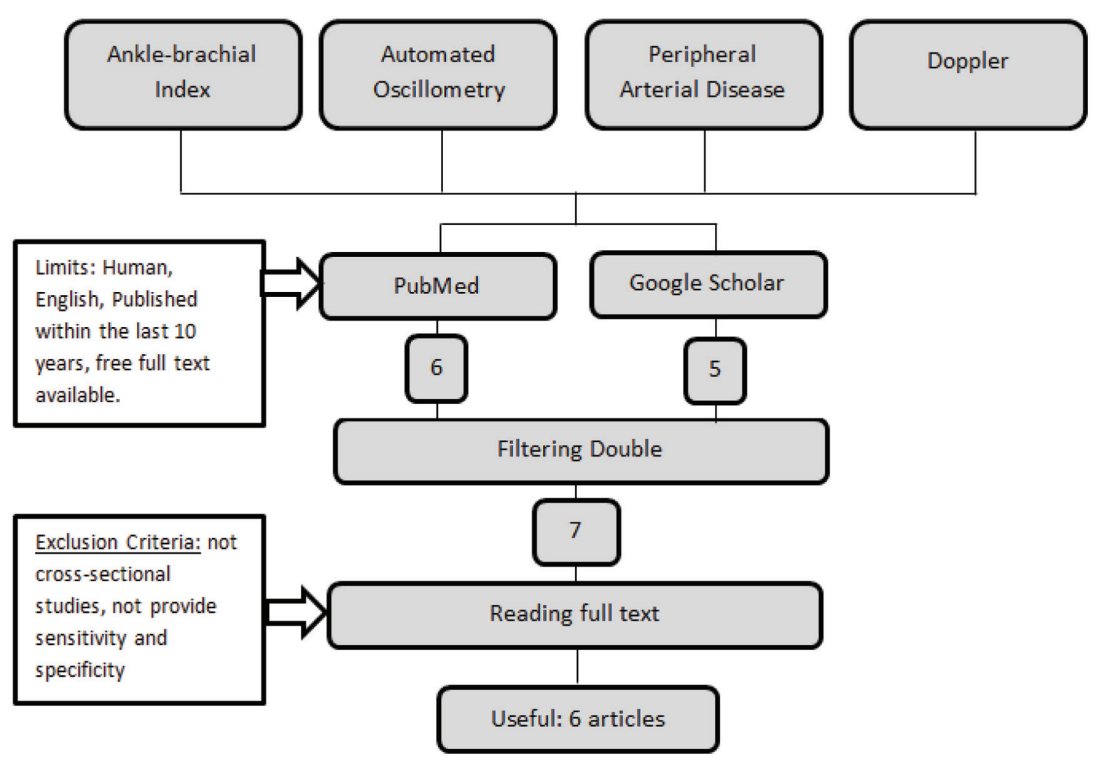

Figure 1 Flowchart of Search Strategy

on high $\mathrm{ABI}$, oscillometry readings seemed to show higher result compared to Doppler measurement.

Takahashi et al. ${ }^{7}$ did a cross-sectional study on 113 subjects recruited from adult health study cohort consisting of atomic bomb survivors. From the study, there were 5 cases of PAD $(\mathrm{ABI}<0.9)$ which was not detected by oscillometry but diagnosed by doppler. It has yielded the sensitivity of 0.5 and specificity of 1 . Since the specificity in $100 \%$, likelihood ratio for the positive result cannot be calculated.

McDougall, et al. ${ }^{8}$ study was a cross-sectional study, which assessed ABI from three different groups of normal volunteers, patients attending a cardiovascular risk clinic, and patients referred to a vascular laboratory. From 57 people in vascular laboratory group, there were 24 of them who had oscillometric reading $<0.9$. The study has yielded a sensitivity of 0.71 and specificity of 0.89 .

Beckman et al., ${ }^{1}$ a cross-sectional study of 201 participants recruited from the vascular laboratory. This study showed that both oscillometry and Doppler determination of blood pressure were very similar, $<3 \mathrm{mmHg}$ apart, with oscillometry sensitivity of 0.73 and specificity of 0.95 . This study showed a good positive predictive value of 0.88 , the highest among other comparable studies.

Clairotte et al., ${ }^{3}$ a cross-sectional study involved 146 patients referred to the physiologic department. From the assessments, patients were separated into diabetic and non-diabetic patients who were at risk of getting PAD. It yielded a low sensitivity of 0.4 , but a pretty high specificity of 0.96 . The study showed that oscillometry reading was more reliable on non-diabetic patients, but it tended to have lower diagnostic performance in diabetic patients.

\section{DISCUSSION}

This systematic review efforts to exhibit the steps of Evidence-Based Medicine (EBM) to answer a clinical question, which is expected to provide an alternative in diagnosing peripheral arterial disease. There were six studies comprised. Each study then critically appraised using Centre for EvidenceBased Medicine, University of Oxford, 2010.

According to the result, Premanath et al., ${ }^{5}$ Korno et al., ${ }^{6}$ Beckman et al., ${ }^{1}$ showed similar sensitivity ranging from $0.7 ; 0.71$ and 0.73 respectively. As well stated in Table 2, all studies have a relatively high specificity. Meanwhile, a study by McDougall et al. ${ }^{8}$ has 0.88 sensitivity, which was the highest value compared to other included studies. The study concluded that automated oscillometry is proven to increase reproducibility of $\mathrm{ABI}$ measurement compared to manual way. However, the tests were taken from the same person, and there was no randomization mentioned in the study. Thus, study bias in this study should be concerned.

On the other hand, a contradicted result presented by Takahasi et al., ${ }^{7}$ the study showed 0.5 sensitivity which was the lowest value among included studies. According to the study, the population included were elderly patients with clear randomization. Similar results were revealed after the Positive Predictive Value (PPV) and Negative Predictive Value (NPV) were calculated, 1 and 0.95 respectively. It can be interpreted that the proportion of people with a positive test who have the condition has no significant difference compared to those who did not have. The Likelihood Ratio for positive in this study cannot be calculated due to its specificity of 1 (100\%). Hence, this may develop study bias. However, for positive point, ABI was measured twice on each participant by one of seven randomly assigned technicians using two methods, the oscillometric and Doppler methods, on both subject's left and right legs.

Another positive note from the studies appraised was that all studies showed positive in reproducibility. Most studies concluded that oscillometry is simple and could be taken in any form of clinical practice, and worked relatively fast. As stated by Premanath et $\mathrm{al},{ }^{5}$ the oscillometric test is an automated test, takes less time, and is less reliant on the specialized skills. Since the test is automated, there will be less bias compared to manual Doppler, which is an examiner dependent test. Also, all studies appraised utilized cross-sectional study design, which is known as the best design for diagnostic studies to evaluate the accuracy of the index test.

Besides the benefits mentioned above, we also acknowledged several limitations. Firstly, this evidence reports only used free-text available 
articles, which might affect the result of this report. Secondly, each study has its method of data collection and analysis. For example, each study collected the data from different arms/legs and different scope of patient populations (non-diabetic and diabetic patients by Claiorette et al). ${ }^{3}$ Finally, each study utilized different types/series with different brands of the index test (automated oscillometric measurement) which might develop study bias.

\section{CONCLUSION}

This systematic review appraised six different studies and concluded that oscillometric method of ABI could be used as an alternative in diagnosing patients suspected with PAD. The test has relatively high specificity; automated oscillometry is comparable with manual Doppler. Since the test is automated, there will be less bias compared to examiner dependent Doppler method. Also, oscillometry required less reliant on the specialized skills, it could be taken in any form of clinical practice, and commonly available, reliable, and simple to use which can be performed by primary care physicians/general practitioners even in their primitive set up.

\section{REFERENCES}

1. Beckman J, Higgins C, Gerhard-Herman M. Automated Oscillometric Determination of the Ankle Brachial Index Provides Accuracy Necessity for Office Practice. Hypertension. 2006; 47: 35-38
2. Versluis B, et al. Functional MRI in peripheral arterial disease: arterial peak flow versus ankle-brachial index. PloS One. 2014 Feb 5; 9(2) e88471. Doi: 10. 1371/journal. pone.0088471. eCollection2014

3. Clairotte C, et al. Automated Ankle-Brachial Pressure Index Measurement by Clinical Staff for Peripheral Arterial Disease Diagnosis in Nondiabetic and Diabetic Patients. Diabetes Care. 2009; 32: 1231-1236

4. Kotovskaya Y, Kobalava Z, Orlov A. Validation of the integration of technology that measures "vascular" indices into ambulatory blood pressure monitoring system. Med Devices (Auckl). 2014; 7: 91-97

5. Premanath $M$, Raghunat M. Ankle-Brachial index by oscillometry: A very useful method to assess peripheral arterial disease in diabetes. Int J Diabetes Dev Ctries. 2010. Apr-Jun; 30(2): 97-101.

6. Korno M, Eldrup N, Sillesen H. Comparison of AnkleBrachial Index Measured by an Automated Oscillometric Apparatus with that by Standard Doppler Technique in Vascular Patients. EurJ Vasc Endovasc Surg. 2009. 38, 610-615.

7. Takahasi I, Furukawa K, et al. Comparison between oscillometric- and Doppler- ABI in elderly individuals. Vascular Health and Risk Management. 2013:9 89-94

8. McDougall A, Tandon V, et al. Oscillometric measurement of the ankle-brachial index. Can J Cardiol. 2008;24(1):49-51.

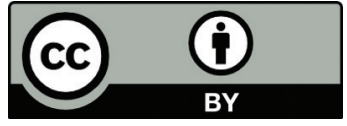

This work is licensed under a Creative Commons Attribution 